\title{
Karl Goldmark und seine letzten Opernwerke
}

\author{
Branko LADIČ \\ Lehrstuhl für Musikwissenschaft \\ Fakultät für Kunst, Comenius Universität \\ Jahodová 19, SK-831 01 Bratislava, Slovakia \\ E-Mail: branko.ladic@gmail.com
}

(Angekommen: März 2016; angenommen: Juni 2016)

\begin{abstract}
Karl Goldmark (1830-1915) was undoubtedly one the most influential composers of the Austro-Hungarian Empire, and through his first opera - The Queen of Sheba - he was also very well-known abroad. This opera, with its very fashionable oriental subject, was first performed in Vienna in 1875 and was one of the greatest successes of the period. After Merlin (1886) and The Cricket on the Hearth (1896), a "song-opera" strongly influenced by the Biedermeier-period, Goldmark wrote three operas over the next ten years. A Prisoner of War (libretto E. Schlicht, premiered in 1899 in Vienna) was based on one episode of the Iliad. In this short opera the composer tried to express the change of Achilles' soul, but he mostly failed due to a relatively weak and conventional libretto and vague musical style. In the following opera, Götz von Berlichingen (libretto A. M. Willner, premiered 1902) the libretto is also the weakest element of the work and the whole opera reminds one of Meyerbeer's operas. The composer found a renewed inspiration during the work on his last opera - The Winter's Tale (libretto by Alfred Maria Willner after Shakespeare, premiered in 1907 in Vienna). This fairy tale opera is full of interesting musical moments and elements written in Goldmark's late style and is still attractive for the opera-going public.
\end{abstract}

Keywords: Karl Goldmark, opera, Die Kriegsgefangene, Götz von Berlichingen, Ein Wintermärchen

Karl Goldmark war unbestritten eine der wichtigsten Persönlichkeiten des $\mathrm{Mu}$ siklebens Österreich-Ungarns und sein Ruhm verbreitete sich auch jenseits der Grenzen des mitteleuropäischen Kulturraumes. Neben seinen Kammer- und Orchesterwerken war es vor allem die Oper Die Königin von Saba, die den Durch- 
bruch in seiner Karriere bedeutete und dem Komponisten den Welterfolg brachte. Heute sehen wir Goldmark in erster Linie als einen Opernkomponisten. Obwohl er nur sechs vollendete Opern hinterließ, ist es sein Opernschaffen, dem er die sorgsamste Aufmerksamkeit widmete. Und nach Die Königin von Saba (1875), mit der sich der Komponist übrigens fast zehn Jahre beschäftigte, bedeuteten auch die folgenden Opernwerke wichtige Ereignisse in seiner Karriere: Merlin (1886) und Das Heimchen am Herd (1896).

Nach Die Königin von Saba, einem Werk, das von der Tradition der Grand Opéra ausgeht, mit starkem Wagner-Einfluss und exotischen Elementen und Inspirationen, die das Werk an die Spitze der damals so starken Welle des Exotismus in der europäischen Opernkunst brachte, komponierte Goldmark seine nächste Oper Merlin auf ein nach Alfred Lord Tennysons Erzählung in Versen verfasstes Libretto von Siegfried Lipiner. Die Vertonung einer Geschichte aus der Zeit und dem Umkreis von König Arthur nähert sich aus musikalischer Hinsicht den Prinzipien von Wagners Musikdrama. Das nächste Opernwerk Goldmarks, Das Heimchen am Herd, bedeutete eine Überraschung. ,Man wollte es gar nicht glauben. Hat Goldmark sich wirklich Dickens' friedliches Heimchen auserwählt für seine neue Oper?", 1 beginnt Eduard Hanslick seine Rezension der Uraufführung. Das Werk ist zwar auch durchkomponiert, doch zugleich in einzelne „Nummern“ mit Rezitativen gegliedert, was allerdings der Absicht des Komponisten entspricht und völlig im Dienst der musikalischen Charakteristik steht.

Die beträchtlichen Abstände zeugen von der Aufmerksamkeit, die der Komponist nicht nur der Wahl und der Bearbeitung der Stoffe für seine neuen Werke widmete, sondern auch von der Sorgfalt, mit der er die einzelnen Opern musikalisch gestaltete. In jedem Fall könnten wir die in allen drei Opern gebrauchten Prinzipien, die das ,glückliche Kompromiss zwischen dem motivisch begleiteten Wagnerschen Rezitativ - und der alten festgefügten Arienoper“" darstellen, als einen Ausgangspunkt betrachten, von dem die musikalische und dramaturgische Gestaltung der folgenden Opernwerke Goldmarks ausgeht, die binnen eines weiteren Dezenniums - bis 1907 - entstanden sind.

\section{Die Kriegsgefangene}

Die Besprechung dieses Werkes kann mit einem Zitat von Hanslick beginnen: „Man kann sich nur mit einiger Anstrengung vorstellen, daß dieses Libretto Gold-

1. Eduard Hanslick, Am Ende des Jahrhunderts (1895-1899). Der „Modernen Oper“ VIII. Teil. Musikalische Kritiken und Schilderungen (Berlin: Allgemeiner Verein für Deutsche Literatur, 1899), 9.

2. Ferdinand Scherber, „Vorwort“, in Karl Goldmark, Erinnerungen aus meinem Leben (Wien - Berlin - Leipzig - München: Rikola, 1922), 7. 
mark begeistert habe. Wahrscheinlich stand ihm kein besseres zu Gebote."3 Das Libretto, das die Geschichte aus dem letzten Buch der Iliade verarbeitet, wurde von Ernst Schlicht geschrieben. Dieser Name ist ein Pseudonym, das der Schriftsteller und evangelischer Teologe Alfred Formey (1844-1901) gebraucht hat.

Die Oper beginnt mit der Totenfeier des Patroklus (Szene 1). Sein Freund Achilles schwört blutige Rache für den Tod des besten Freundes und lässt den an den Wagen geknüpfte Leichnam Hektors tagelang um den Mauern Trojas schleifen (Szene 2 - Achilles' Klage). Achilles' göttliche Mutter Thetis ermaht ihn vergebens, der Rache zu entsagen (Szene 3). Da meldet man dem Held, dass seine Sklavin Briseis gewagt habe, die Leiche Hektors in ein Linnen zu hüllen. Achilles will sie mit dem Tod bestrafen (Szene 4), ihr würdevolles Auftreten beruhigt ihn aber und er befiehlt, sein Schiff für Briseis' Heimreise vorzubereiten (Szene 5). Im zweiten Akt lässt sich der schlaflose und von Albträumen verfolgte Achilles von Briseis, die ihm den Heiltrank bringt und ein Lied singt, beruhigen (Szene 1). Bald danach tritt in das Zelt der trojanische König Priamos, der um die Leiche seines Sohnes Hektors fleht, zuerst vergebens. Schließlich lässt sich aber Achilles erweichen und gibt dem Vater den Leicham seines unglücklichen Sohnes aus. Der dankbare Priamos zieht ab (Szene 2) und das große Liebesduett zwischen Achilles und Brieseis bildet den Schluss der Oper (Szene 3).

Was Goldmark am meisten angezogen haben mag, war wohl nicht die bekannte und oft bearbeitete Episode aus der Geschichte des trojanisches Krieges. Es war vielmehr die „Verwandlung“ Achilles, die durch Milde und Liebe von Briseis bewirkt wird. Dieser Tendenz - der Bemühung, intime Seelenregungen des antiken Helden zu vergegenwärtigen - entspricht auch der ,,intime“ Schauplatz der Handlung in beiden Akten - das Innere des Zeltes von Achilles. Diese interessante Lesart scheiterte allerdings an der zu konventionellen Ausführung des Libretto. Nicht unbedingt die Aufteilung der einzelnen Szenen der knappen Handlung, die relativ arm an dramatischen Geschehnissen und Wendungen ist (Goldmark war ein Theatermann mit sicherem dramatischem Instinkt), sondern vor allem die Qualität der Verse scheint problematisch zu sein. Der wütende Achilles seufzt etwa im zweiten Akt in allzu konventioneller Manier: „O Briseis! Ich bin so krank. So wund, so weh, [...] Liebst du mich? Du liebst mich?" Und so weiter.

In der musikalischen Gestaltung des Werkes können wir die für Goldmark charakteristische Methode identifizieren: die Zusammenstellung der verschiedenen musikalischen Einflüsse und Stilelemente. Neben rein romantischer, idiomatisch an Mendelssohn und Schumann erinnernder Musik (Achilles Phrase: „Wie wundersam! Mir das ein Weib!...“ - Notenbeispiel 1) ist das dominierende musikalische Element deutlich Wagnerscher Herkunft, besonders in der Dekla-

3. Eduard Hanslick, Aus neuerer und neuester Zeit. Der „Modernen Oper“ IX. Teil. Musikalische Kritiken und Schilderungen (Berlin: Allgemeiner Verein für Deutsche Literatur, 1900), 5. 
Notenbeispiel 1 Die Kriegsgefangene, „Wie wundersam!...“
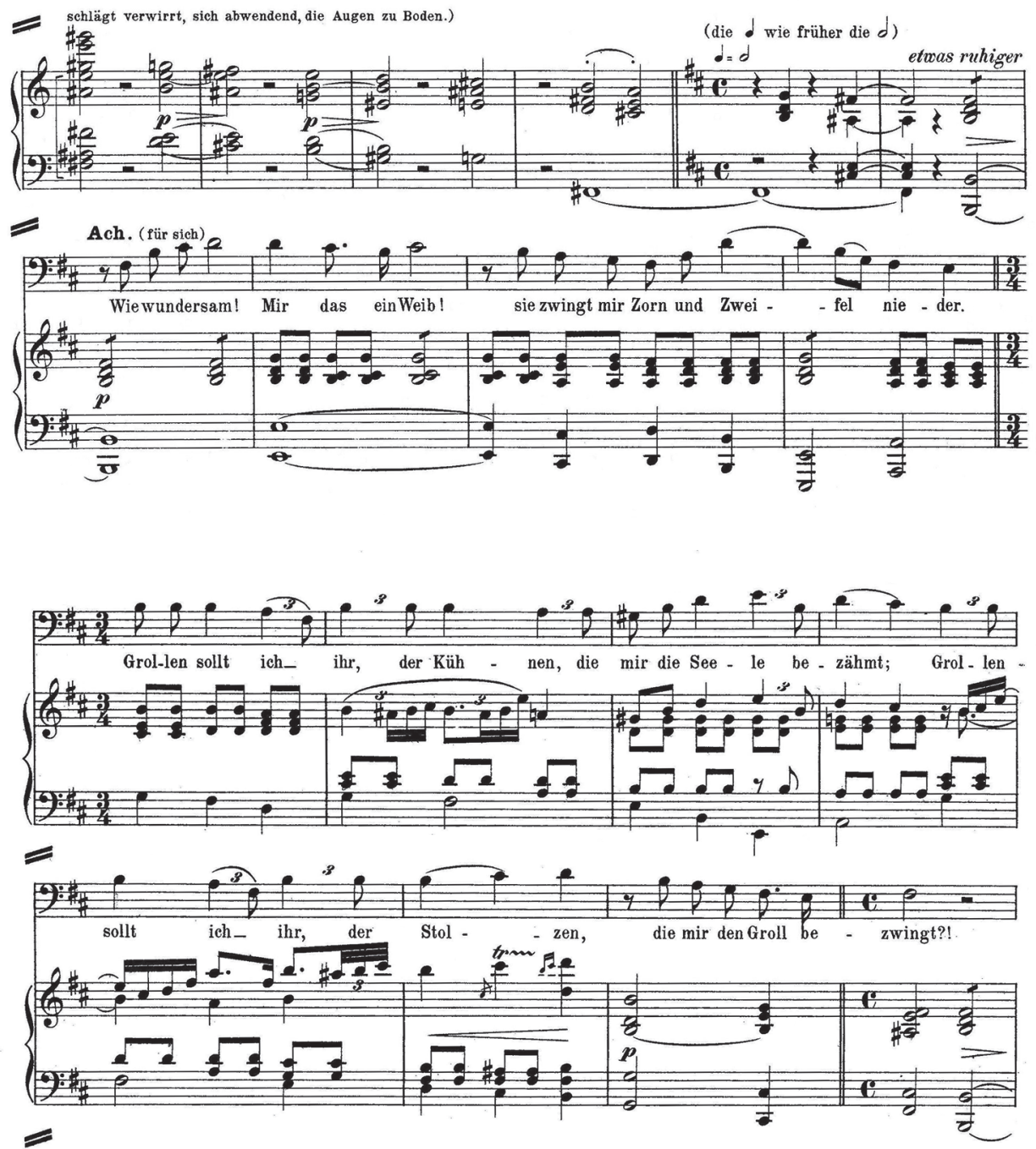

mation und der Art der Textvertonung. Wagners harmonische Welt (Chromatik, Vorhaltstechnik), die die musikalische Sprache Goldmarks wesentlich beinflusste, dominiert in den intimen Szenen (Achilles Klage, Notenbeispiel 2). Kontrastierend wirkt dazu das thematische Material der Briseis (Notenbeispiel 3).

Es geht um die Stelle, wo zum ersten Mal die Stimme der Briseis zur expressiven melodischen Linie sich ausschwingt. Die verwendeten Parallelismen bringen einen Kontrast zum vorigen musikalischen Verlauf (siehe Notenbeispiel 1) und wirken als interessante musikalische und auch dramaturgische Innovation - ein guter Beweis, dass Goldmark die neuesten Strömungen der europäischen Musik 
NotenbeISPIEl 2 Die Kriegsgefangene, Achilles Klage

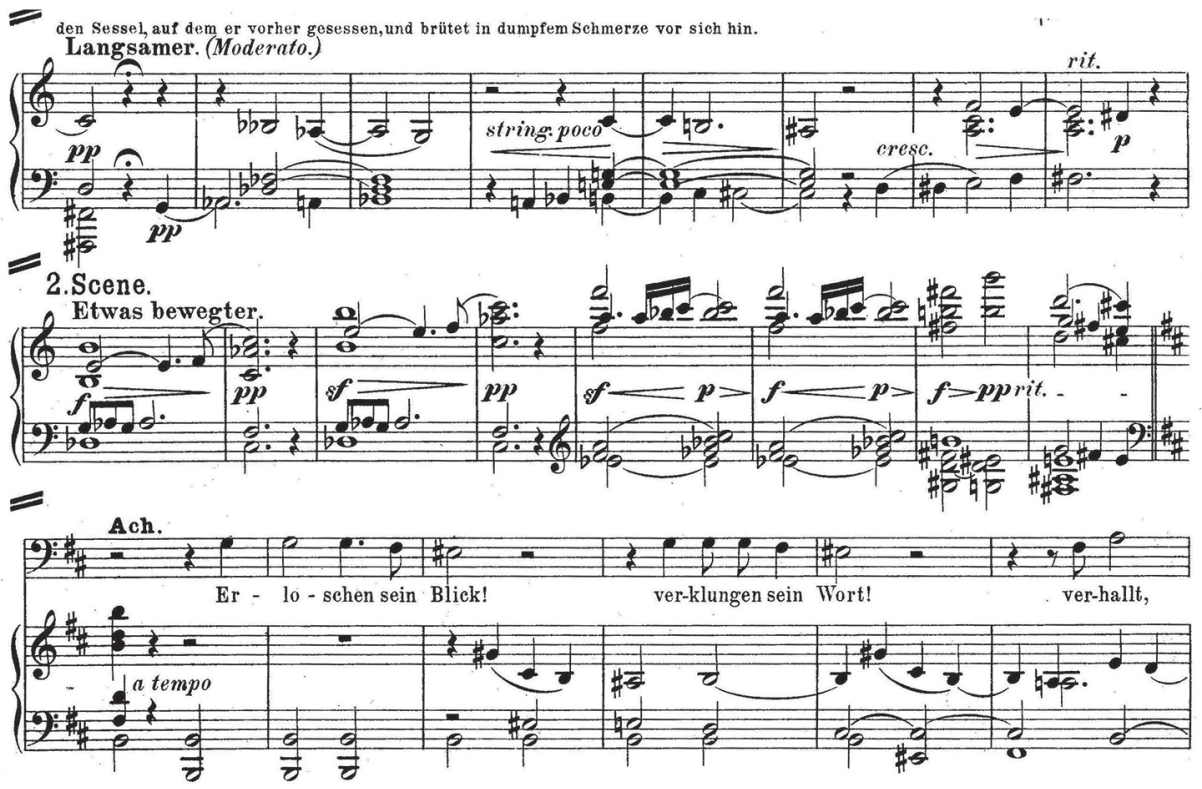

reflektierte. Quintakkord-Parallelismen verbreiteten sich durch den musikalischen Impressionismus und dessen Einfluss auf dem Gebiet der Oper (Verismo). Dieses Mittel wurde aber schließlich auch schon von Giuseppe Verdi verwendet (siehe z. B. die Szene der Desdemona im vierten Akt von Otello, bei ihrer Erzählung über die Dienerin Barbara „Amava un uom, che poi l'abbandonò...“, oder in seinem Requiem, in Confutatis bei den Worten „Oro supplex et acclinis...“). Es geht immer um Stellen oder Situationen vom sehr intensivem, meist negativem oder magischem Ausdruck, was übrigens auch bei Goldmark der häufigste Fall ist, wie z. B. bei Briseis' Gesang: „Von Lethe trinken darfst du noch nicht...“.

Konventioneller wirken die Ensemble- und Chorszenen. In der Anfangsszene, der Totenfeier für Patroklus, die übrigens eine der musikalisch expressivsten Stellen im ganzen Werk darstellt, könnten wir in den Akkordfolgen in Terzverwandschaft fast beethovenschen Pathos erkennen (Notenbeispiel 4). Der Chor tritt mit einem musikalischen Material ein, das noch an vorklassische Muster erinnert (Notenbeispiel 5). Die fallenden Sekunden bzw. Sekundschritte binnen einer kleinen (Moll-)Terz sind ganz offensichtlich ein Mittel der traditionellen Affektentheorie. Am konventionellsten sind die Kriegsaufrufe (,Zur Schlacht! Zum Sieg!..."), die der Komponist auch am Ende des Werkes verwendet (unlogisch, weil kurz davor den Trojanern ein zwölftägiger Waffenstillstand zur Bestattung Hektors bewilligt worden ist), wohl als ein Mittel zur Stärkung dramaturgischer Einheit des Werkes (Notenbeispiel 6). 
Notenbeispiel 3 Die Kriegsgefangene, Briseis

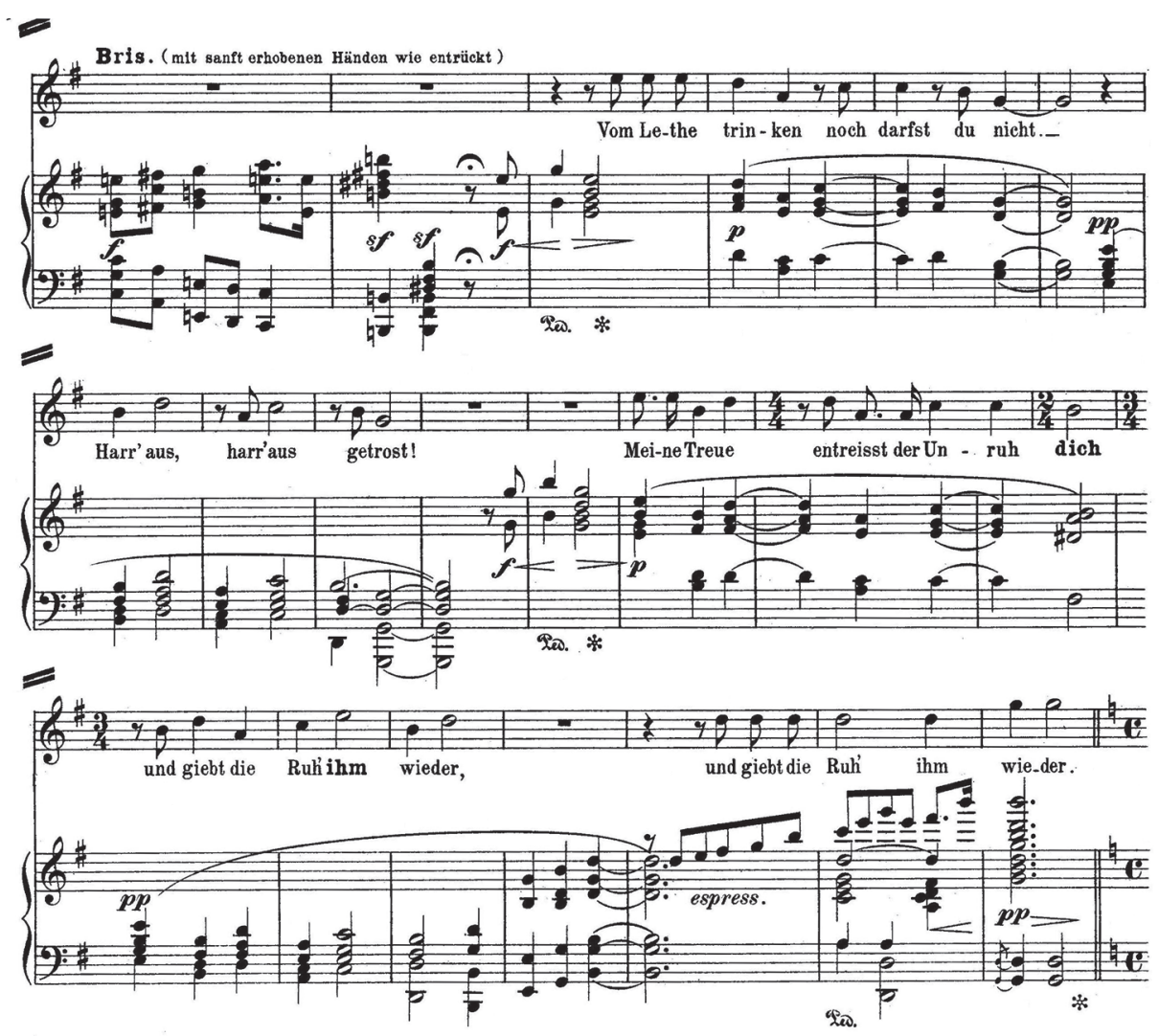

NotenbeISPIEl 4 Die Kriegsgefangene, Totenfeier

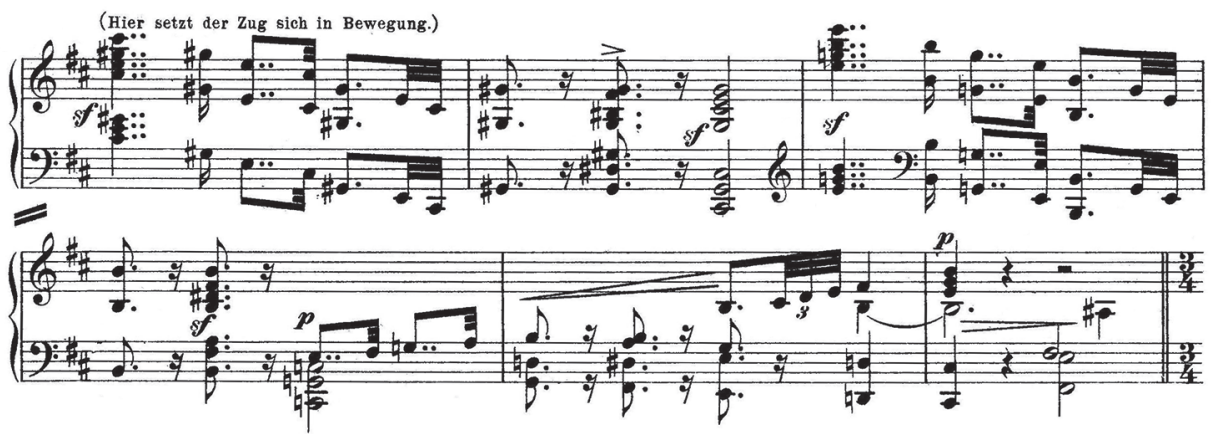


Notenbeispiel 5 Die Kriegsgefangene, Totenfeier

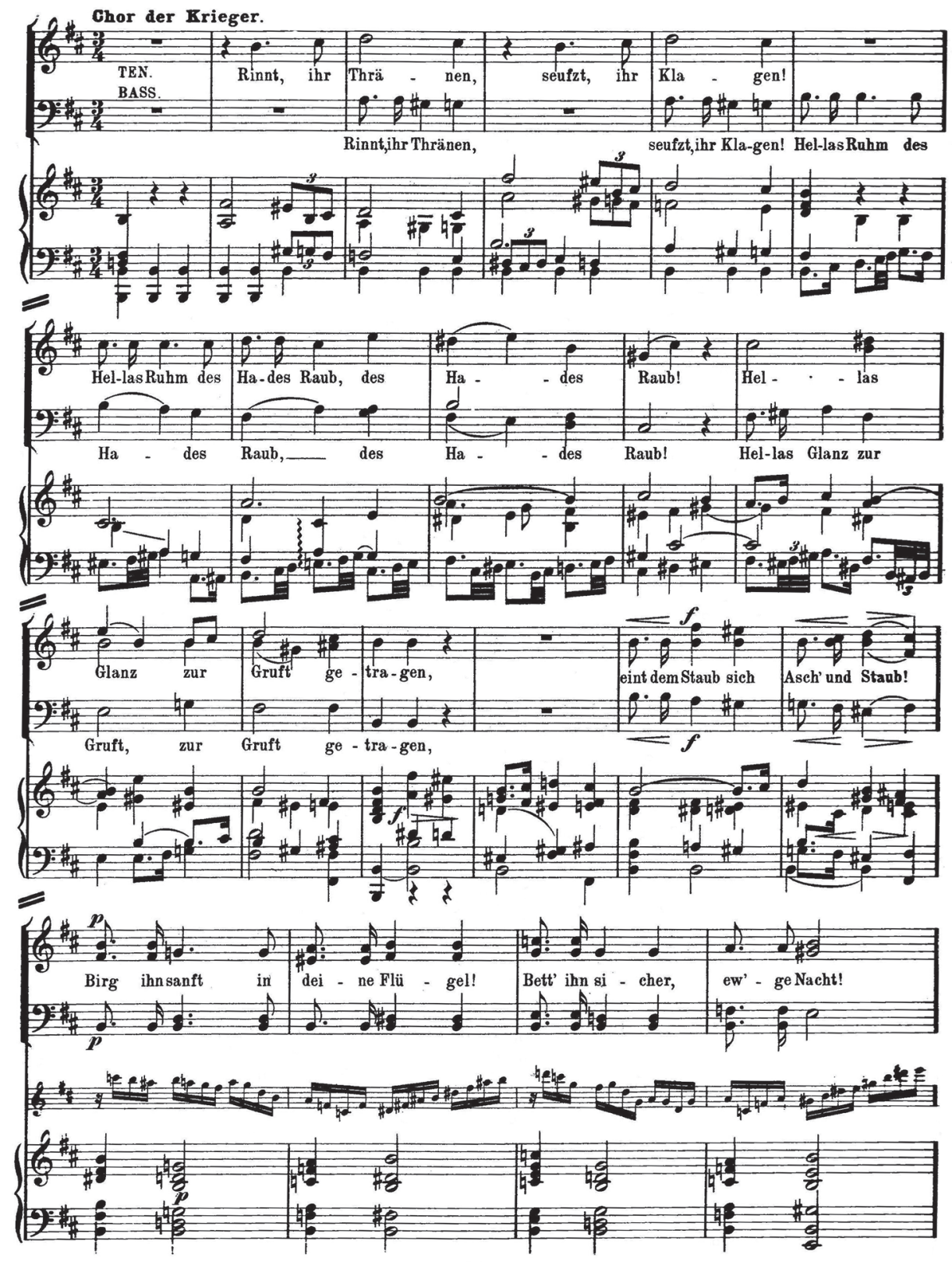


Notenbeispiel 6 Die Kriegsgefangene, Schluss

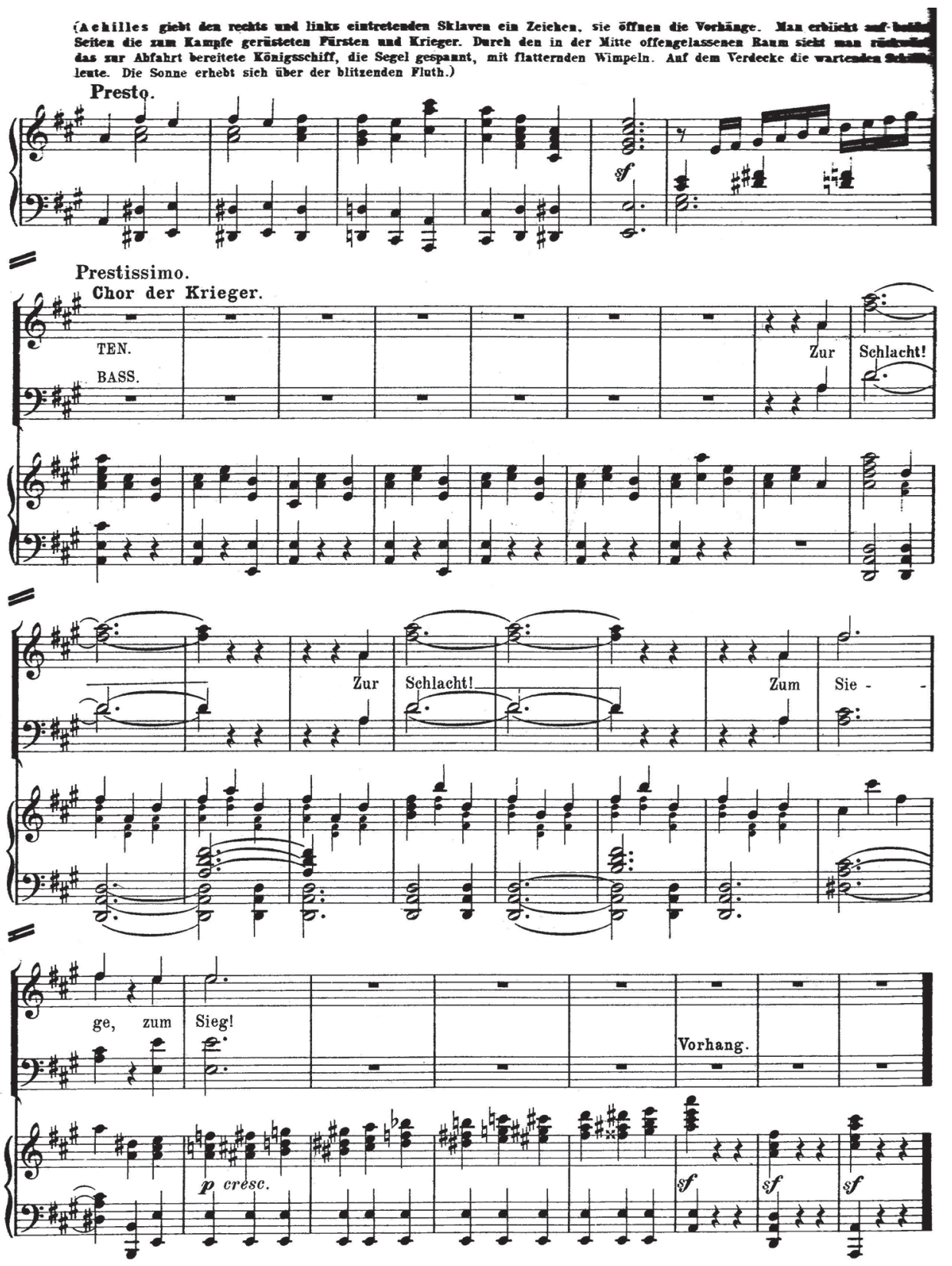


NotenBeISPIEL 7 Die Kriegsgefangene, Apell

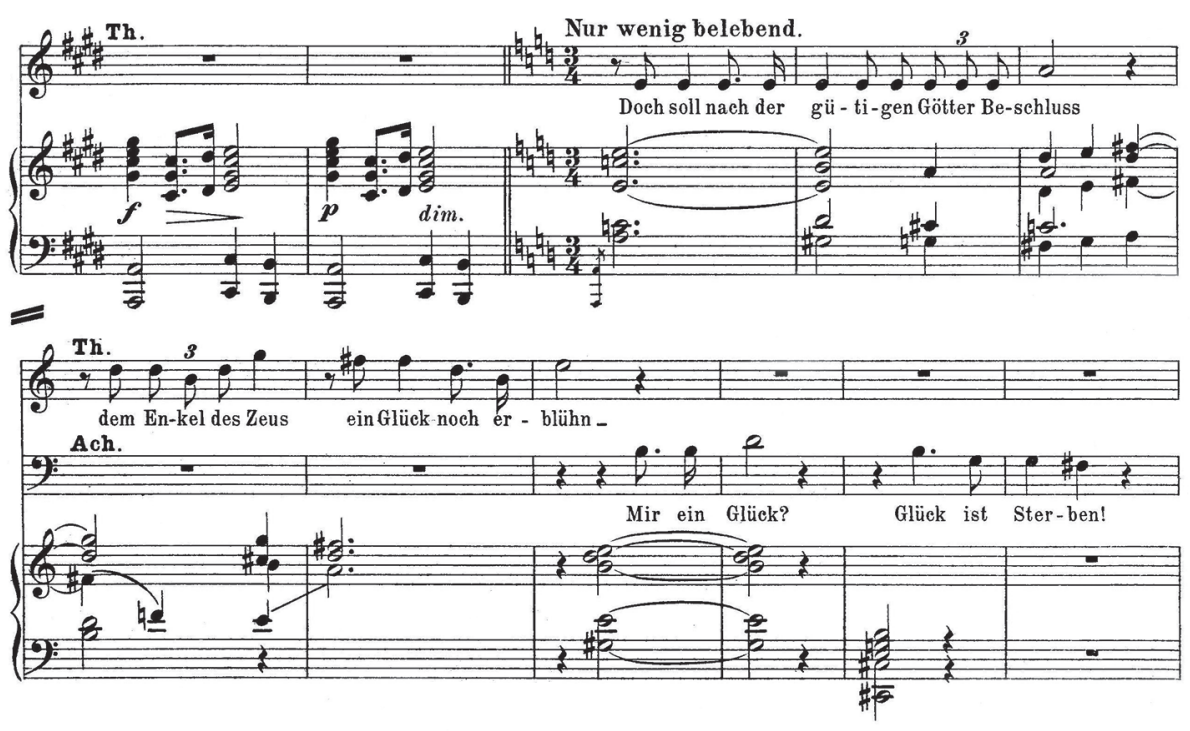

Die Gliederung der beiden Akte in Szenen schließt jedoch die weitere Gliederung in rezitativische und ariose Abschnitte innerhalb der einzelnen Szenen nicht aus. Goldmark verfährt relativ raffiniert und ersetzt die rein rezitativischen $\mathrm{Ab}$ schnitte, die im Werk sehr selten sind, mit expressiven und konzentriert deklamatorischen Abschnitten, die dem fließenden musikalischen Verlauf förderlich sind. Neben der Klage Achilles' (Akt I, Szene 2, siehe Notenbeispiel 2) geht es z. B. um die dritte Szene - „Apell“" von Thetis (Notenbeispiel 7). An dieser Stelle basiert die Melodik der Thetis vor allem auf dem Deklamieren auf einem Ton oder auf den Tönen des Quintakkordes. Dieses Verfahren verleiht dem Gesang der Thetis einen zeremoniell-erhabenen Charakter. Der Auftritt der Briseis (Szene 4) stellt einen relativ langen Abschnitt dar, in dem die Schüchternheit der angeklagten Sklavin durch die Art ihrer Deklamation ausgedrückt wird (Notenbeispiel 8).

Die erwähnten Deklamationsabschnitte sind durch Stellen von expressiver Kantabilität ausgewogen - z. B. den Abschnitt am Ende des ersten Aktes (siehe Notenbeispiele 2-3) oder das Lied der Briseis („Im rauschenden Forst bei Regennacht...", Akt II, Szene 1), das zwar deklamatorisch mit dem Orchestereintritt beginnt, später aber zum expressiven Zwiegesang von Briseis und Achilles übergeht, oder auch das Schlussduett von Briseis und Achilles (,So hab’ ich dich endlich gewonnen“). Interessant ist die Totenfeier für Patroklus zu Beginn der Oper (Szene 1), die mit Chor- und Orchestereinwürfen und Achilles Klagerufen fast oratorisch wirkt. 
Notenbeispiel 8 Die Kriegsgefangene, Szene 4

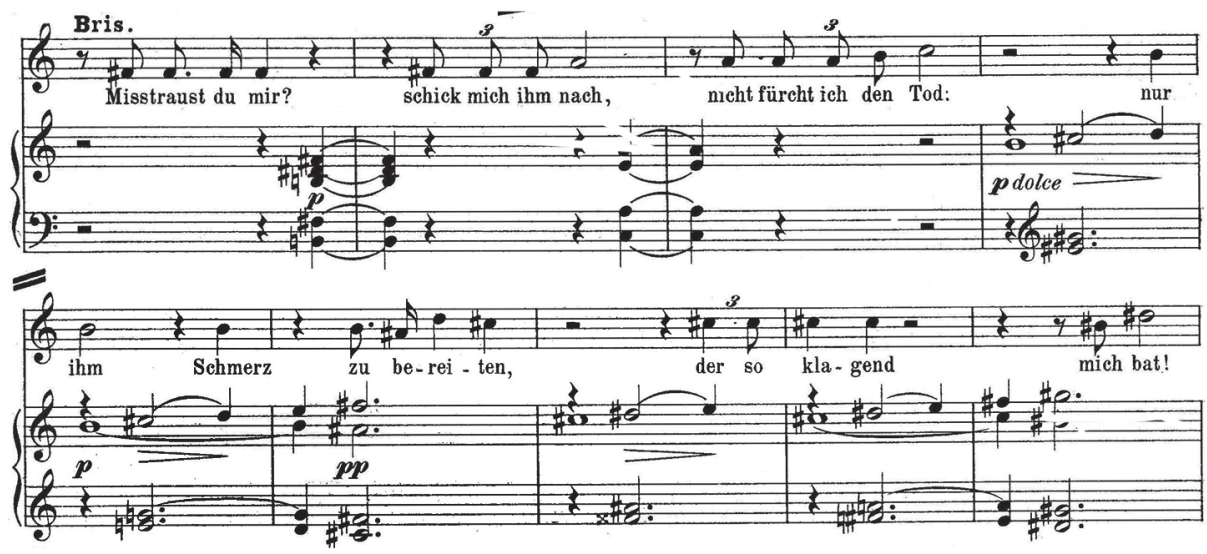

Für die musikalische Charakteristik der handelnden Personen benutzt der Komponist Motive, die den Rahmen einer akzidentellen Leitmotivik ${ }^{4}$ nicht überschreiten und keineswegs zur Grundlage des Ausbaus der ganzen musikalischen Struktur werden. Neben dem thematischen Material von Achilles und Briseis, das Goldmark auch im umfangreichen Vorspiel zum 2. Aufzug verwendet, wirkt das Motiv des um die Leiche des Sohnes flehenden Priamos besonders stark.

„Die neue Oper erfreute sich einer durchaus günstiger Aufnahme“"5 - schrieb Hanslick in seiner Rezension über die Uraufführung des Werkes, die am 17. Januar 1899 an der Hofoper in Wien stattfand. Der Erfolg des kurzen Stückes (es dauert nicht einmal 90 Minuten) war jedoch nicht nachhaltig. Die Kriegsgefangene überschritt nicht den Schatten eines Achtungserfolgs.

\section{Götz von Berlichingen}

Götz von Berlichingen ist die einzige Oper Goldmarks, die nicht an der Hofoper in Wien uraufgeführt wurde. Der Komponist schrieb sie für die Budapester königliche Oper, wo sie am 16. Dezember 1902 auf die Bühne gebracht wurde. Es ist ein Paradox, dass Goldmark für das für das erste Theater seines Heimatlandes bestimmte Werk einen genuin deutschen Stoff wählte - das gleichnamige Schauspiel Goethes. Zudem geht es um eine relativ komplexe Handlung, die den ,ganz neuen Reichtum des Lebens aller Stände, vom Kaiser bis zum elenden Reichssoldaten“

4. Die in diesem Artikel gebrauchten Begriffe aus der Theorie der Oper und des Musikdramas stammen von Carl Dahlhaus; siehe Carl Dahlhaus, Wagners Konzeption des musikalischen Dramas (Kassel - Basel London - New York: Deutscher Taschenbuchverlag - Bärenreiter, 1978).

5. Eduard Hanslick, Aus neuerer und neuester Zeit, 9. 
NotenBEISPIEL 9 Götz von Berlichingen, Götz

\section{Qöłz vor Berlichingen. oper in 5 Akten \\ Carl Goldmark.}
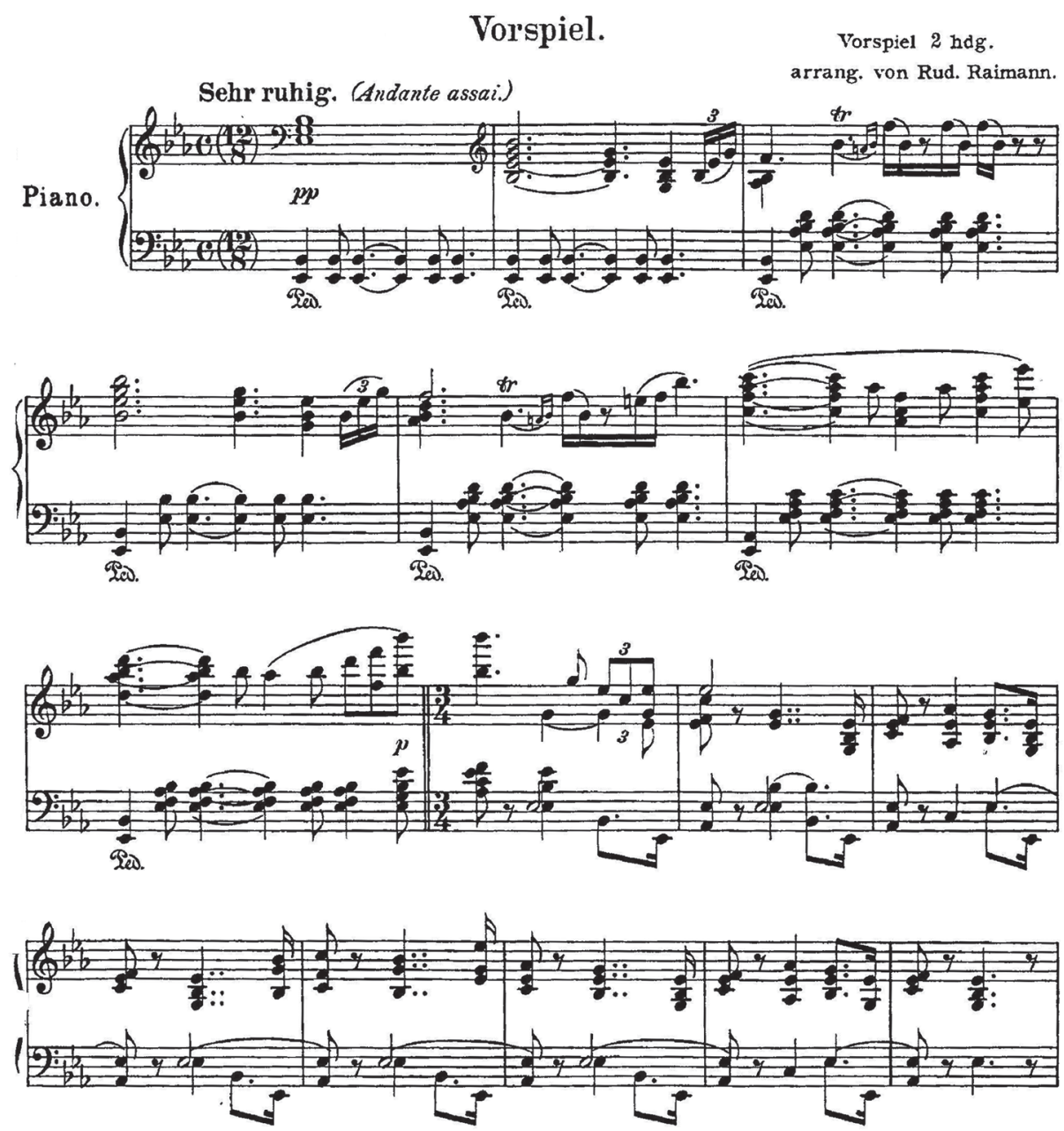
Notenbeispiel 10 Götz von Berlichingen, Götz
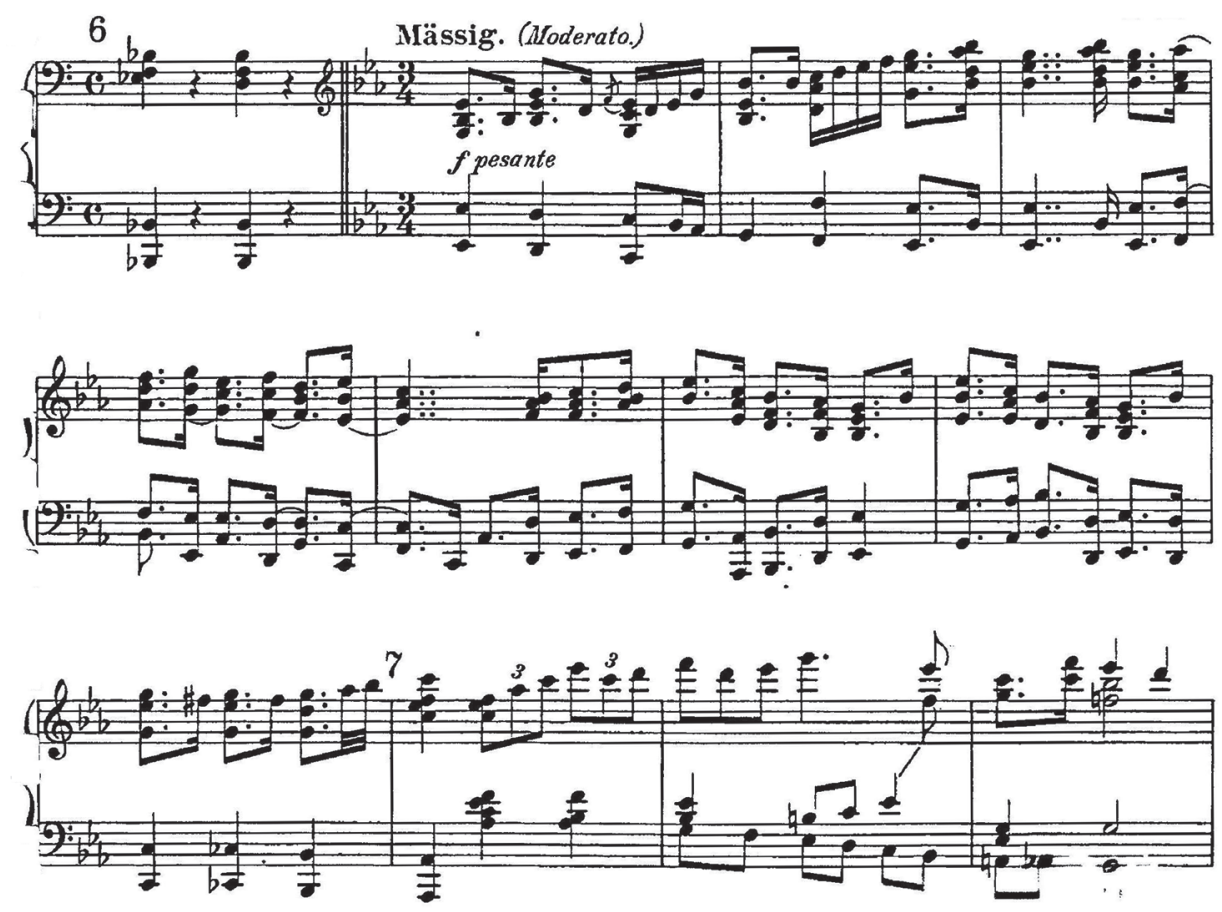

darstellt, „,die überaus mit Gegensätzen, gern hart nebeneinander“ arbeitet und „auch nach Shakespeares Vorbild Ernstes und Komisches verschränkt“". ${ }^{6}$ Die Bearbeitung der Vorlage für die Opernbühne von Alfred Maria Willner (1859-1929, Librettist der Oper Das Heimchen am Herd, 1896, 1897 schrieb er das Libretto für die letzte Operette von Johann Strauß - Die Göttin der Vernunft, später bedeutender Operetten-Librettist u. a. von Franz Lehár) ist aber nicht glücklich geraten. Sie vereinfachte die Handlung stark, was den gedanklichen Inhalt sowie das literarische Niveau des Librettos beeinträchtigte. Das Ergebnis war ein Plot, der auf äußerst konventionellen dramaturgischen Situationen basiert, deren Gestaltung sehr nahe am bewährten Modell Meyerbeers und Scribes stand. 
Notenbeispiel 11 Götz von Berlichingen, Adelheid
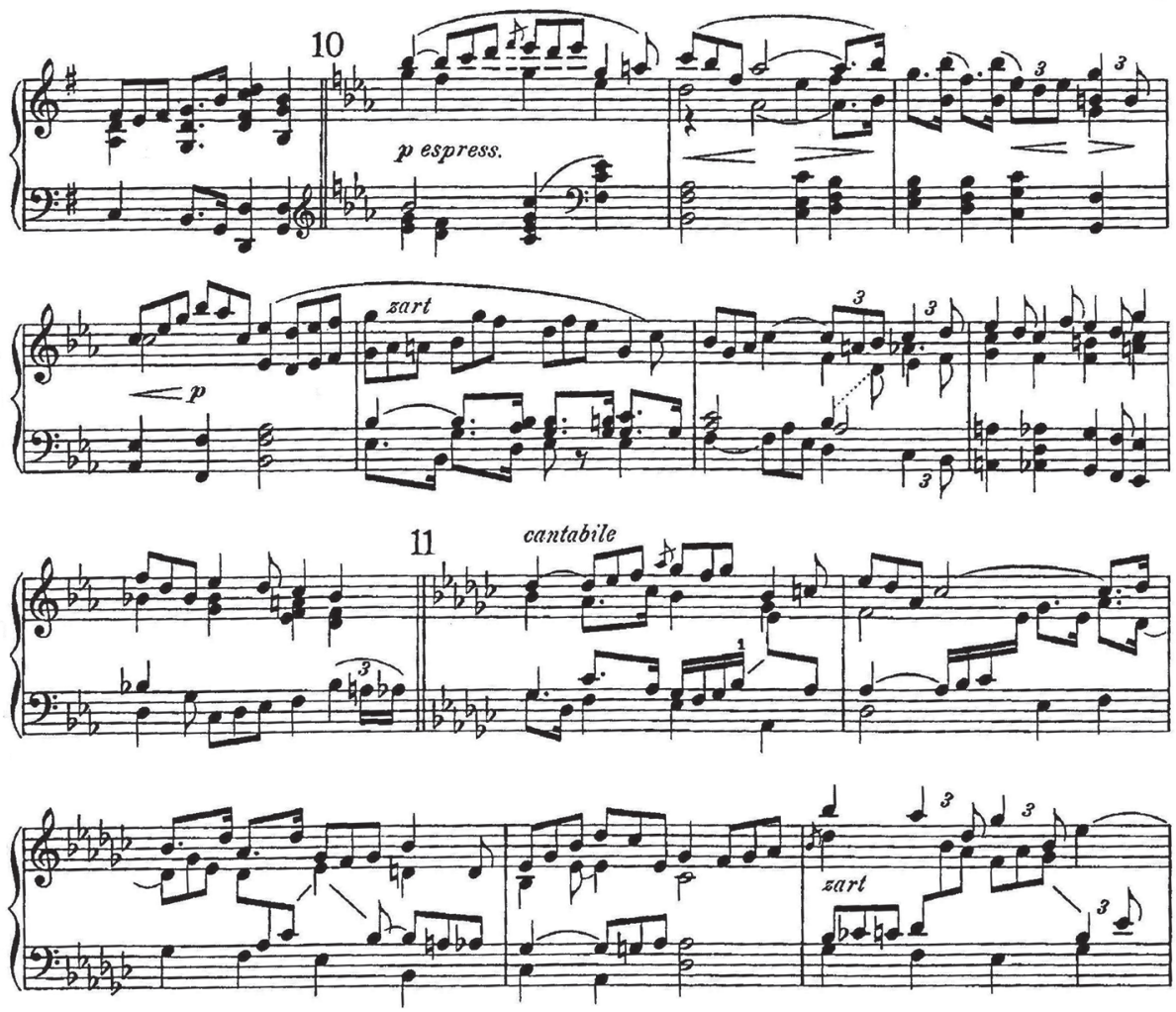

Notenbeispiel 12 Götz von Berlichingen, Franz

Sehr langsam und schwer.

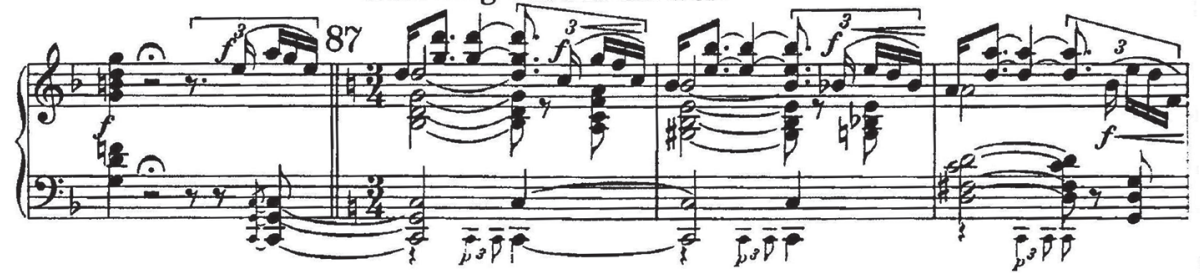

(Franz durch die Thüre rechts, verstaubt, in Reiterstiefeln, verneigt sich vor Allen, dann zu Weislingen.)

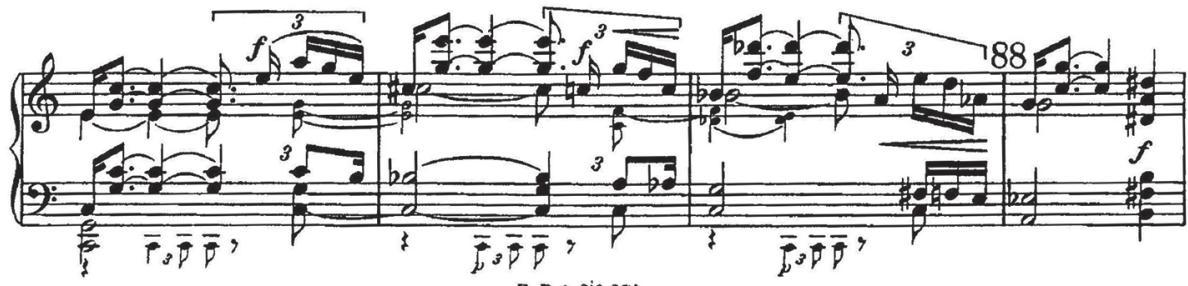


NotenBeisPiel 13 Götz von Berlichingen, Götz
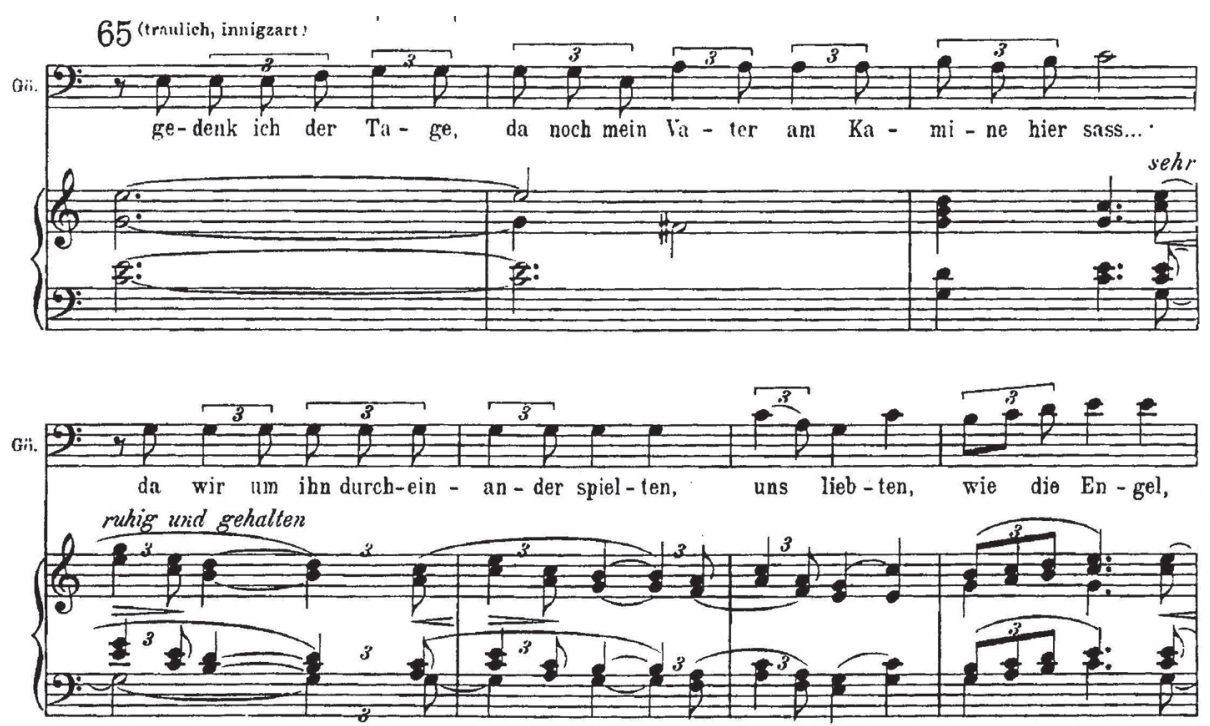

Der Librettist gliederte die komplizierte Handlung der Vorlage in fünf Akte und neun Bilder:

\author{
Akt I: Saal bei Götz (fünf Szenen) \\ Akt II \\ Abteilung 1: Ratszimmer zu Heilbronn (eine Szene) \\ Abteilung 2: Am Hofe des Bischofs von Bamberg (fünf Szenen) \\ Akt III \\ Abteilung 1: Waldlichtung (eine Szene) \\ Abteilung 2: Kaiserlicher Hof zu Augsburg (drei Szenen) \\ Akt IV: Landschaft, Bauernaufstand (drei Szenen) \\ Akt V \\ Abteilung 1: Schlosspark bei Weislingen \\ Abteilung 2: Schlafgemach in Adelheids Schloss \\ Abteilung 3: Götz im Gefängnis
}

Gewiss war es eine schwere Aufgabe, den komplizierten und umfangreichen Stoff der Vorlage, die eigentlich ein gesellschaftlich-geschichtliches Fresko des frühen 16. Jahrhunderts ist, in ein Libretto umzuwandeln. Die Tatsache ist im ersten Akt der Oper besonders spürbar, wo mehrere, nicht zusammengehörende Szenen des Schauspiels zusammengeschweißt wurden - Weislingens Verlobung mit Maria, der Schwester von Götz, Georgs Lied vom Knaben, der ein Vögelein fing, die Einladung nach Heilbronn oder die Kunde Franzens von der Anwesenheit der 
NotenBeispiel 14 Götz von Berlichingen, Götz im Gefängnis
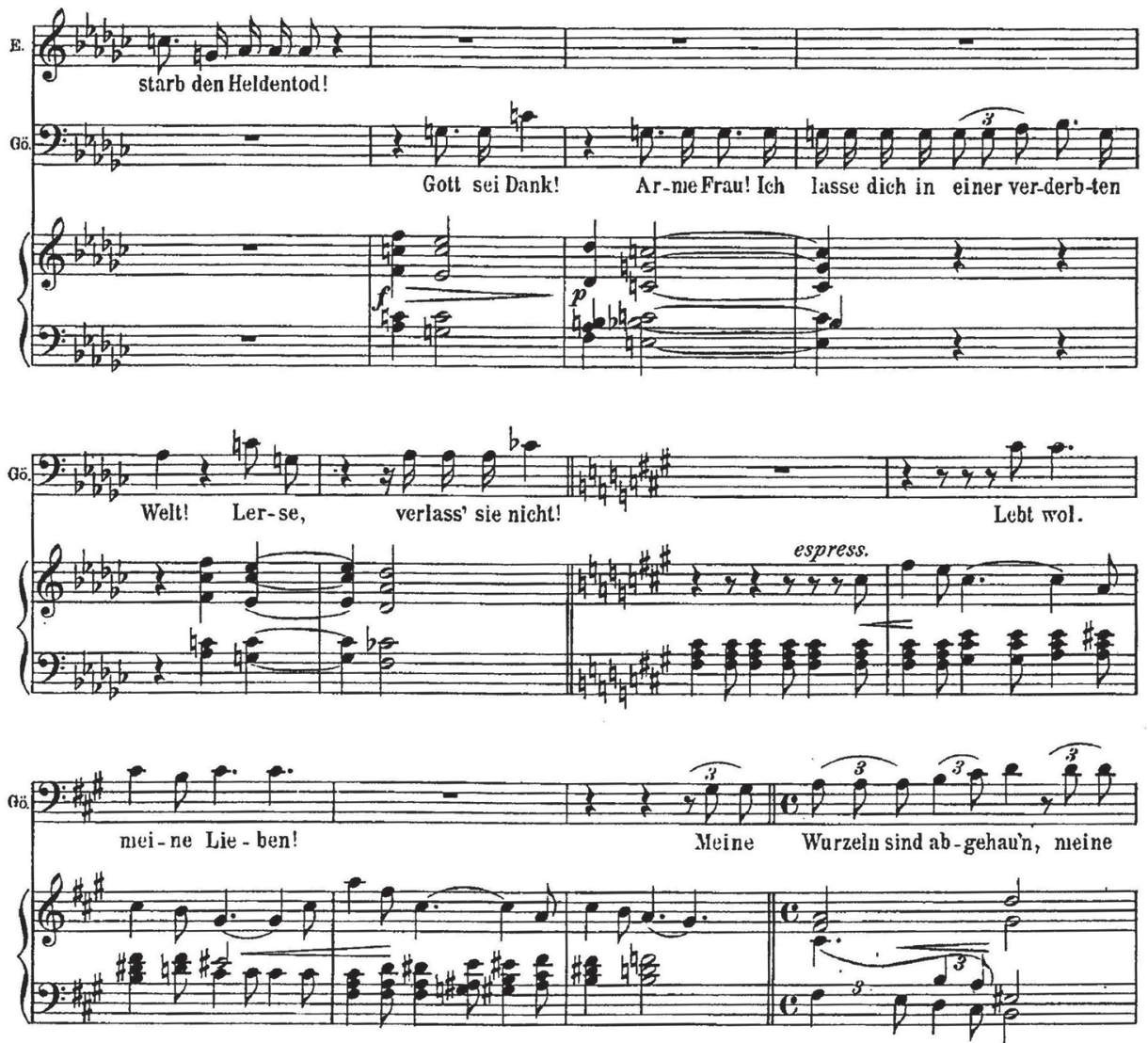

schönen Adelheid am Hof des Bischofs von Bamberg. Die Gerichtsszene (Szene 10 des fünften Aktes der Vorlage) wurde in der Umgestaltung des Librettisten zu einem konventionellen Verschwörungsauftritt (Akt V, Abteilung 1), der dem Verschwörungsauftritt aus dem vierten Akt der Hugenotten von Meyerbeer (1836) ähnelt. Andererseits exponiert der Librettist die dramaturgisch äußerst wirksame Szene der Erdrosselung der Adelheid von einem der Vehmerichtern (Akt V, Abteilung 2) auf offener Bühne - es geht um die Szene, die Goethe in der Endfassung seines Schauspiels vermied (in der ersten Fassung des Werkes war sie enthalten, Goethe hat allerdings später sechs von neun Auftritten der Adelheid in den drei letzten Akten gestrichen ${ }^{7}$ ). Dieser Opernszene, die den dramaturgischen und musikalischen Höhepunkt des Aktes darstellt, gehen allerdings eine konventionelle 
lyrische Arie („,Komm, komm, Wandrer, komm, du süßer Knab'...“) und ein aufgeregtes Rezitativ, eine Art „Wahnsinnszene“, vor.

In der Bearbeitung des Librettisten gibt es mehrere Beispiele, die aus der Perspektive der traditionellen Operndramaturgie zwar wirksam sind - neben Kyrie eleison aus der Ferne am Ende des zweiten Aktes etwa die Pagen-Szene (Abteilung 2 des zweiten Aktes, Szene 4) oder auch der Bauernaufstand mit dem wilden Tanz am Ende des vierten Aktes (hier wird eine andere Parallele zu Meyerbeer deutlich, und zwar zu Der Prophet). Es handelt sich aber andererseits um dramaturgische Mittel, die anno 1902 als anachronistisch bezeichet werden konnten.

Musikalisch ist das Werk im Allgemeinen im Vergleich mit der vorigen Oper konzentrierter. Dem Komponisten ist es sogar gelungen, die bereits erwähnten Schwächen des Librettos musikalisch zu kompensieren. Er stattet einzelne Personen mit Motiven bzw. mit motivischem Apparat aus, wobei der Rahmen einer akzidentellen Leitmotivtechnik wieder einmal nicht überschritten wird. Es geht vielmehr um so genannte Erkennungsmotive. Die Oper ist formal durchkomponiert, die Gliederung der Struktur ist jedoch mehr oder weniger deutlich erkennbar. Die Idiomatik und Gestaltung der Motive (also nicht die Struktur des Gewebes, nur Melodik und Harmonik) und die Vertonung des Textes weisen mehr auf die Wagnerschen Prinzipien hin, was Götz von Berlichingen in die stilistische Nähe von Merlin rückt. Die Oper wird durch ein umfangreiches, im relativ freier Form komponiertes Vorspiel eingeführt. Darin wird der Kontrast zwischen dem thematischen Material von Götz (Notenbeispiele 9-10) und dem von Adelheid (Notenbeispiel 11) ausgespielt - als eine Art Kontrast zwischen männlichem und weiblichem Prinzip, sehr ähnlich wie im Vorspiel zum zweiten Akt der Oper Die Kriegsgefangene. Das Tempo wird allmählig schneller: Sehr ruhig - Mäßig - zweimal „Belebend“ und „Sehr schnell“ (sehr interessant ist die Angabe des Komponisten: Sehr schnell, Tempo des letzten Satzes der A-dur Symphonie von Beethoven). Die ganze Oper gehört zu den glänzendsten Beispielen von Goldmarks Instrumentierungskunst. Neben dem Leit- (oder besser) Erkennungsmotiv der Adelheid oder dem rhythmisch prägnanten Motiv des Franz (Notenbeispiel 12) spielt das thematische Komplex eine wichtige Rolle, das sich mit der Person des Götz verbindet. Neben den schon erwähnten Götz-Motiven (siehe Notenbeispiele 9-10) exponiert der Komponist ein zweites Motiv (Notenbeispiel 13). Dieses taucht im Werk mehrmals wieder auf, in leicht veränderter Form etwa auch in der Todesszene des Titelhelden im Gefängnis (Notenbeispiel 14).

Götz von Berlichingen war in der Heimat des Komponisten, in Österreich-Ungarn, eigentlich nur ein Achtungserfolg gegönnt (auch der Wiener Aufführung der neuen Fassung von 1910). Günstigerer Aufnahme erfreute sich das Werk in Deutschland, was wir wohl eher dem Stoff als seiner Bearbeitung zuschreiben können. 


\section{Ein Wintermärchen}

Der Komponist wählte für seine nächste Oper, die seine letzte werden sollte, Shakespeares gleichnamiges Schauspiel aus dem Jahr 1610. Dies bewährte sich als eine äußerst glückliche Wahl. Im Schauspiel begegnen wir typischen märchenhaften Figuren und Wendungen: ein eifersüchtiger König, der seine Gemahlin zu unrecht verstoßen will, eine durch ein Wunder gerettete Prinzessin, die auf einem Bauernhof aufwächst und dort zufällig einem Prinzen begegnet, die wunderbare Entdeckung ihrer königlichen Herkunft, Auferstehung der toten Mutter... Auch Ort und Zeit der Handlung sind fantastisch: Sie spielt in Sizilien und in Böhmen vor Christi Geburt. Viele Shakespeare-Kenner und -Theoretiker bemühten sich, auch den besonderen Titel des Werkes zu erklären. Nach Charles H. Herford ${ }^{8}$ signalisiert der Titel dem Publikum, dass es sich hier um eine unwahrscheinliche Geschichte, um ein Märchen handelt, welche man Kindern während der langen Winterabende erzähle. Das alles inspirierte wohl Goldmark, den „Feind des Gewöhnlichen“,9 zur Schaffung einer fantastischen Oper, einer Art Feérie, was ihm auch musikalisch auszudrücken gelungen ist. (Was anderes könnte auf einem böhmischen Bauernhof vor Christi Geburt getanzt werden, als ein Wiener Walzer?)

Das Libretto wurde für den Komponisten wieder von Alfred Maria Willner erarbeitet, dem die Arbeit an einem derartigen Stoff viel mehr lag. Es gibt ja bereits in der Vorlage quasi „operettenhafte“ bzw. feérienhafte Elemente, besonders im zweiten Akt. Die drei ersten Akte der Vorlage bilden inhaltlich den ersten Akt der Oper, die übrigen Akte stimmen mit der Gliederung der Vorlage überein.

Musikalisch bildet die Oper den Höhepunkt von Goldmarks spätem Schaffen. Erster und dritter Akt weisen elegische Grundstimmung auf, der zentrale zweite Akt, der auf einem böhmischen Bauernhof spielt, bietet einen Kontrast dazu und unterstreicht die formale Geschlossenheit des Ganzen. Die Gliederung der einzelnen Szenen der formal durchkomponierten Oper in rezitative und Arioso-Abschnitte ist zwar deutlich, aber sehr gut ausgewogen, was der Übersichtlichkeit und dem Ablauf des musikalischen Gewebes förderlich ist. Die gebrauchten Motive werden während des Werkes verändert und bilden somit thematische Komplexe, die sich auf Personen der Handlung beziehen. Notenbeispiel 15 zeigt das Arioso des Leontes, während in Notenbeispiel 16 die Arie der Herminia zu sehen ist.

Trotz dieser konzentrierten thematischen Arbeit müssen wir wieder feststellen, dass die Leitmotivtechnik additiv ist - Goldmark verwendet einzelne Motive als gelegentliche musikalische Charakteristik, die Leitmotivik wird nicht zur Basis für die Entwicklung des musikalischen Gewebes im Sinne von Wagners Musik-

8. Charles Harold Herford (ed.), The Winter's Tale. The Warwick Shakespeare Edition (London: Blackie and Son, o. J.), XV.

9. Hanslick, Am Ende des Jahrhunderts, 3. 
Notenbeispiel 15 Ein Wintermärchen, Arioso des Leontes
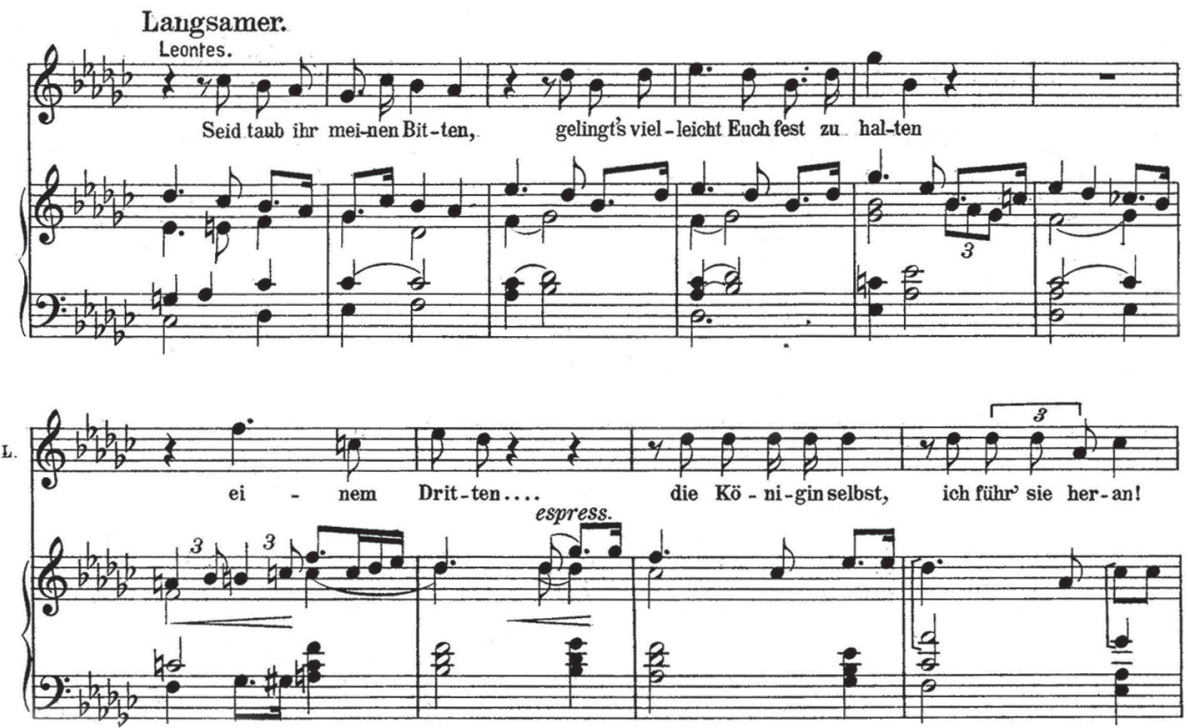

drama. Goldmarks Werke bleiben Opern. Damit hängt die dominierende Periodizität der Struktur (die Leitmotivik im Sinne Wagners und musikalische Periodizität schließen sich, mindestens tendenziell, aus ${ }^{10}$ ). Die periodische Struktur und ihre relative Einfachheit, und zwar in elegischen sowie in lyrischen Momenten, am meisten in den liedhaften Ausschnitten im zweiten Akt, wiegt Goldmark mit der Verwendung von chromatischen Akkordfolgen und Wendungen, vor allem von Akkorden der chromatischen Terzverwandtschaft, aus. Damit schließt sich der Komponist der damaligen Tendenz an, zu deren Höhepunkten unbestritten Der Rosenkavalier und Ariadne auf Naxos von Richard Strauss werden sollte (siehe Notenbeispiel 17, Chor aus dem zweiten Akt). Wir müssen auch orchestralen Abschnitte erwähnen - zwei Vorspiele (zum ersten und zum zweiten Akt), die der Einführung in die Grundstimmung der einzelnen Akte dienen und von der Reifheit des orchestralen Stils des späten Goldmark zeugen. 
Notenbeispiel 16 Ein Wintermärchen, Aria der Herminia

76
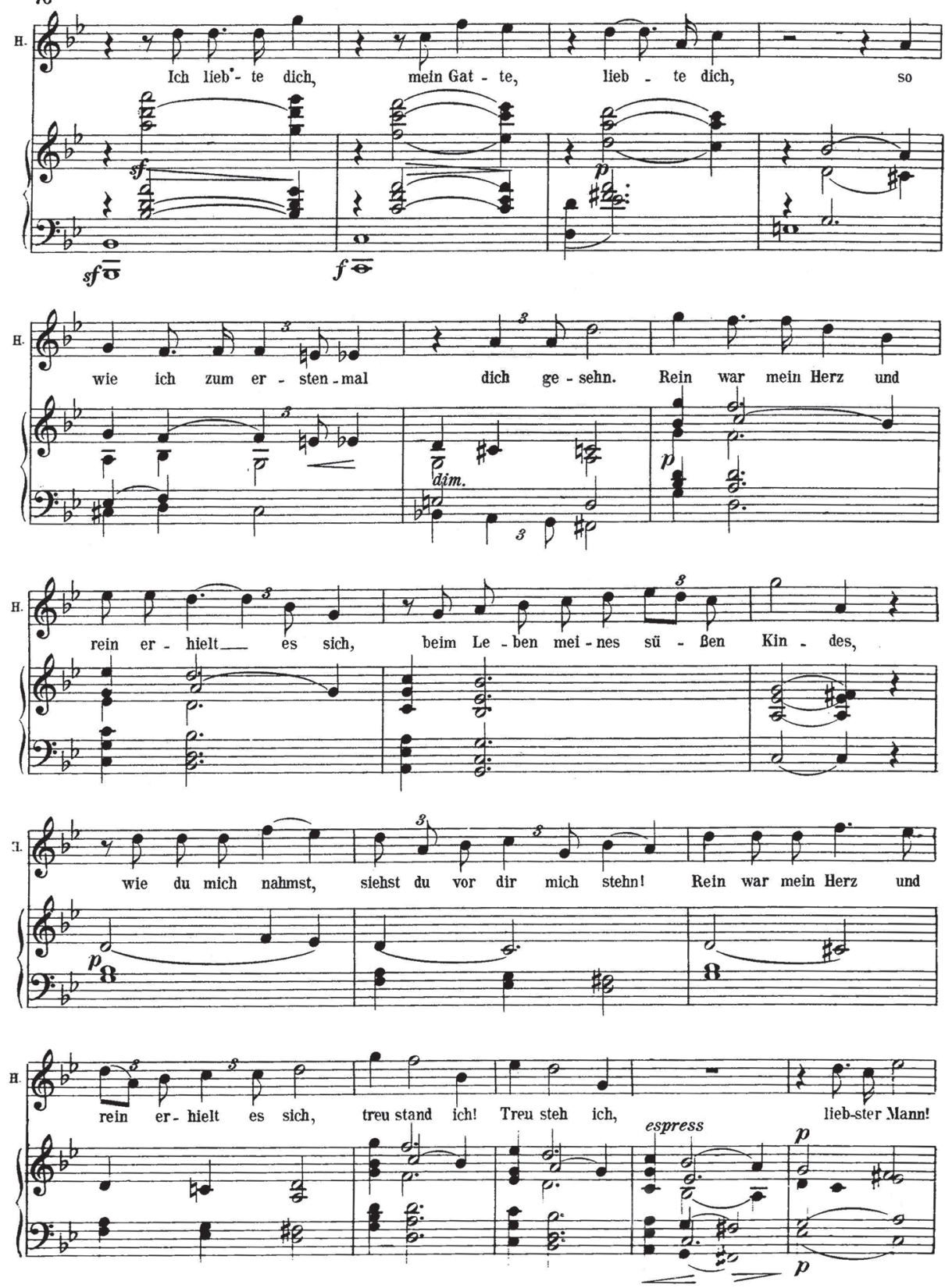


\section{Zum Schluss}

Aus unseren Betrachtungen resultiert, dass von den letzten drei Opernwerken Karl Goldmarks mindestens Das Wintermärchen auch heutzutage das Potenzial zur theatralischen Umsetzung haben dürfte. Woran liegt es dann eigentlich, dass das Schaffen Goldmarks in Vergessenheit geriet? 1875, zur Zeit der Uraufführung seiner Erstlingsoper Die Königin von Saba galt der Komponist als Vertreter der neuesten Tendenzen im Opernschaffen - der attraktiven, modischen „orientalen“ Dramaturgie und der vom orientalen Lokalkolorit stark geprägten musikalischen Gestaltung. Die Oper hat er bereits 1871 abgeschlossen, aber es dauerte dem Anfänger vier ganze Jahre, bis er ihre Aufführung durch die Wiener Hofoper erreicht hat. Goldmark erwähnt in seinen Erinnerungen, wie schmerzhaft für ihn die Wiener Aufführung von Giuseppe Verdis Aida war, des Werkes, das auf denselben dramaturgischen und musikalischen Prinzipien basierte. ${ }^{11}$ Das Heimchen am Herd (1896), eine stilistisch vom Biedermeier inspirierte Oper, war für

Notenbeispiel 17 Ein Wintermärchen, Akt II, Chor
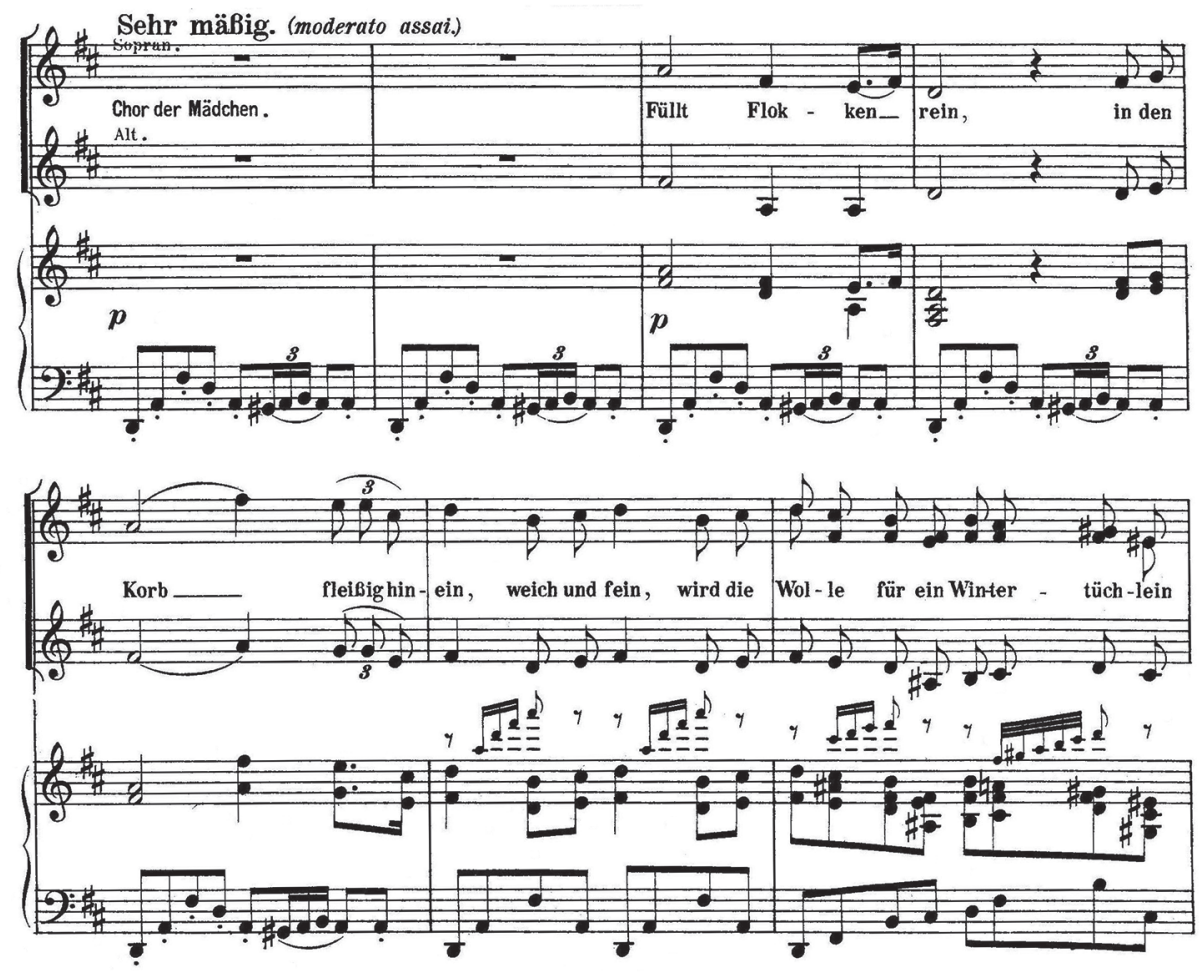

11. Karl Goldmark, Erinnerungen, 124. 
Notenbeispiel 17 Ein Wintermärchen, Akt II, Chor

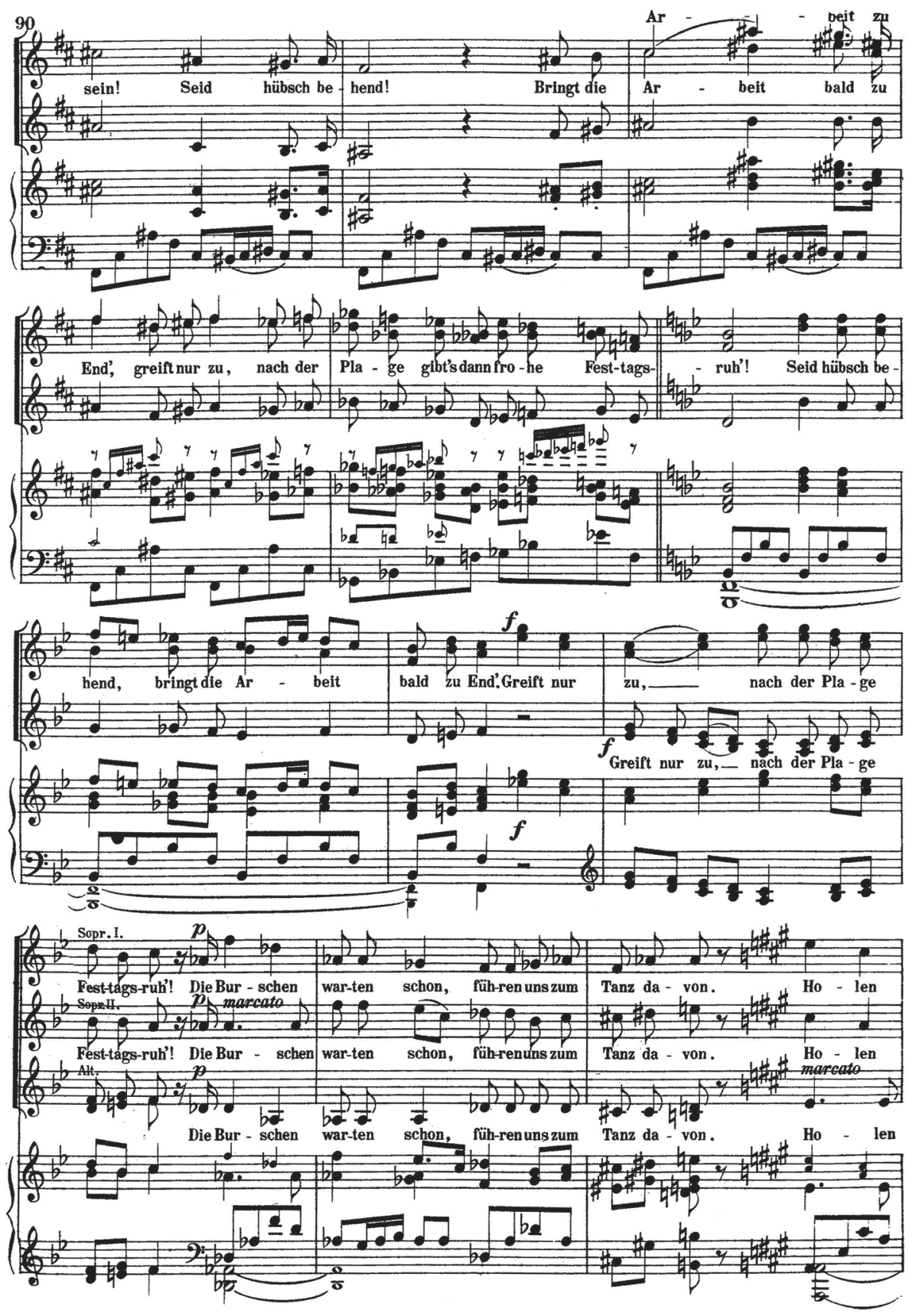


die damalige Opernwelt eine angenehme Überraschung - ein Werk, das mit der damals im mitteleuropäischen Raum stark dominiereden Wagner-Epigonenwelle kontrastierte.

Was ist bei der Rezeption der drei letzten Opern Goldmarks das Problematischste? Meiner Meinung nach ist es vor allem die dramaturgische Gestaltung der Werke und das literarische Niveau ihrer Libretti. In diesem Bereich scheint der Komponist die Entwicklung und die Hauptströmungen im Opernschaffen seiner Zeit wenig zu reflektieren. Bei Die Kriegsgefangene scheiterte sein relativ innovativer Akzent auf die Seelenzüge des Titelhelden auf der äußerst konventionellen Textgestaltung. In Götz wirkt die viel zu traditionelle Konzeption der einzelnen Szenen störend. Wegen des fantastischen Sujets der letzten Goldmark-Oper, das der damaliger Zeit und der Atmosphäre des Fin-du-siècle am besten entsprach, wurde Das Wintermärchen, obwohl nicht nachhaltig, zum Welterfolg - auch die musikalische Inspiration scheint hier am stärksten zu sein. Wir haben schon erwähnt, dass Goldmark auch in hohem Alter die neuesten Tendenzen in der Musik verfolgt hat - etwa die chromatischen Akkordfolgen in Das Wintermärchen wirken sehr modern und frisch, obwohl es sich dabei um das Werk eines fast 80-jährigen Komponisten handelt.

Was die spätere Aufnahme und Wirkung der Opern von Karl Goldmark betrifft, spielt auch die problematische Identität des Komponisten eine wichtige Rolle. Goldmark gehörte der k. u. k. Habsburger-Monarchie an und sein Lebensweg ist sozusagen typisch österreichisch-ungarisch. Er wurde in Keszthely in Ungarn, in einer deutschsprachigen jüdischen Familie geboren. Er beherrschte die ungarische Sprache nicht, aber im Revolutionsjahr 1848 wurde er zum Honvéd und kämpfte gegen die kaisertreue Armee. Später studierte und arbeitete er in Wien, erlebte dort seine Erfolge, gesellschaftliche und künstlerische Annerkennung. Als leidenschaftlicher Tourist kannte er die österreichischen Gebirgen sowie die adriatische Küste. 1910 wurde ihm das Ehrendoktorat der Budapester Universität verliehen und er wurde Ehrenbürger der Heimatstadt Keszthely. Goldmark selbst hielt sich für einen - modernen! - österreichischen Komponisten, was ihn natürlich nicht daran hinderte, ein ungarischer Patriot zu sein. Ferdinand Scherber erklärt ihn in seinem Vorwort zu Goldmarks Erinnerungen (1922) für einen Wiener Komponisten („Er war Geist, Seele dieser Stadt...") ${ }^{12}$ und reiht ihn eigentlich in ein respektables Komponisten-Triumvirat ein: Johannes Brahms - Johann Strauß - Karl Goldmark. Dabei bezieht sich das Sujet keiner seiner sechs Opern auf das Gebiet oder auf die Geschichte der Länder der k. u. k. Monarchie. Vor allem die sozusagen schwankende Nationalität des Komponisten ist meiner Meinung nach der Hauptgrund seiner gegenwärtigen Position in der europäischen Musikgeschichte - das ist übrigens auch bei Meyerbeer, der ein wichtiges Vorbild Gold- 
marks war, der Fall, und zwar nicht - wie auch bei Goldmark - allein wegen seiner jüdischen Herkunft. Kosmopolitismus wurde nach dem Ersten Weltkrieg und nach der Gründung der Nationalstaaten im mitteleuropäischen Raum nicht nur unmodern, sondern inakzeptabel. Und während Johann Strauß, zwar als Populärkomponist, zu einem Symbol Österreichs geworden ist, und Johannes Brahms noch zu Lebzeiten eine wichtige Figur der deutschen Musikkultur geworden ist, blieb Goldmark nach dem Zerfall der Donaumonarchie sozusagen heimatlos - als gebürtiger Ungar und als ein bewusster Österreicher. 
